\title{
2006-230: ENGINEERING IN A MORALLY DEEP WORLD
}

\section{George Catalano, State University of New York-Binghamton}

Dr. Catalano is a Professor of Mechanical Engineering. He researches and teaches in the areas of engineering design, the fluid dynamics of the natural world and applied mathematics and is included in the Philosophers' Index for his work in environmental ethics 


\title{
Engineering in a Morally Deep World
}

\begin{abstract}
A new code of ethics is offered for engineering and is compared and contrasted to presently existing codes. Present day engineering codes are examined and their linkage to models of the natural world from the Middle Ages through the Age of Enlightenment is explored. A new model for the natural world, nature as a self-organizing system is described. A self-organizing system is characterized by synthesis rather than analysis and suggests a new code of ethical responsibility based upon community rather than individuality. Using the model of nature as a self-organizing system, a new code of ethics for engineers is offered. Having established the importance of community of interests in questions involving engineering responsibilities towards the environment, the notion of a morally deep world is extended to include the interests of those often ignored or unheard: the working poor, the sick and enfeebled, children and the elderly, all those dispossessed or powerless in our society.
\end{abstract}

Keywords: Engineering ethics, codes of conduct, models of nature, a morally deep world

\section{Introduction}

Engineering applies technical knowledge to solve human problems. More completely, engineering is a technological activity that uses professional imagination, judgment, integrity, and intellectual discipline in the application of science, technology, mathematics, and practical experience to design, produce, and operate useful objects or processes that meet the needs and desires of a client. ${ }^{1}$ Today engineering is seen as a profession which refers specifically to fields that require extensive study and mastery of specialized knowledge and a voluntary and abiding commitment to a code of conduct which prescribes ethical behavior. The present work explores the notion of ethical behavior as outlined in various codes of conduct in engineering today and offers a more expansive view of what it means to be an ethical engineer in the context of a morally deep world.

The discussion will begin with an examination of the existing codes of conduct offered by various engineering societies and engineering education accrediting agencies. After that discussion, an effort will be made to explain how exactly engineering arrived at this point in its understanding of ethical responsibility. A new paradigm will be offered for engineering one based on a morally deep world view as first formulated in environmental ethics. Finally, with this new foundation of ethics in place, an argument will be made that the promotion of social justice is equally relevant in careful consideration of engineering decisions. If the natural world is identified as having interests and being a part of a greater community, is it in turn equally as important to include the interests of other members of the human family whose voices are rarely if ever heard in engineering - the voices of the poor, of indigenous peoples, of the sick, the old, and the dispossessed?

\section{Reviewing the Codes of Ethics and Conduct}


At the start of the $21^{\text {st }}$ century, there are as many different codes of conduct in engineering as there are engineering disciplines and specialties. One professional society, the National Society for Professional Engineers (NSPE), has offered one general code which is widely employed today in all the disciplines as well as in engineering education. The NSPE Code of Ethics consists of a preamble followed by a listing of fundamental canons and then rules of practice. ${ }^{2}$ The very first canon cautions engineers in the fulfillment of their professional duties, to "hold paramount the safety, health and welfare of the public." As a result, the first rule of practice states that engineers shall "hold paramount the safety, health, and welfare of the public." Note that the explicit requirements focus on the public only though presumably concern for the natural world in included implicitly though only as it affects humankind.

The American Society of Mechanical Engineers (ASME) sets forth a similarly constructed code of ethics with fundamental principles followed by fundamental canons. ${ }^{3}$ The first principle states that engineers uphold and advance the integrity, honor, and dignity of the Engineering profession by using their knowledge and skill for the enhancement of human welfare. The supportive fundamental canon states engineers shall hold paramount the safety, health and welfare of the public in the performance of their professional duties.

The American Society of Civil Engineers (ASCE) does at least mention the environment in its code. ${ }^{4}$ According to ASCE, Engineers uphold and advance the integrity, honor and dignity of the engineering profession by using their knowledge and skill for the enhancement of human welfare and the environment (fundamental principle) and shall hold paramount the safety, health and welfare of the public and shall strive to comply with the principles of sustainable development in the performance of their professional duties (fundamental canon). There is no explanation of what is meant by the enhancement of the environment. In November 1996, the ASCE Board of Direction adopted the following definition of sustainable development: "Sustainable development is the challenge of meeting human needs for natural resources, industrial products, energy, food, transportation, shelter, and effective waste management while conserving and protecting environmental quality and the natural resource base essential for future development." 5

The Institute of Electrical and Electronics Engineers (IEEE) Code of Ethics states that its members accept responsibility in making engineering decisions consistent with the safety, health and welfare of the public, and to disclose promptly factors that might endanger the public or the environment. ${ }^{6}$ Here, an interesting notion of responsibility towards the environment is described. It is not in opposition to the IEEE code to endanger the public or the environment only to not disclose promptly factors that might endanger the public or the environment.

The Institute of Industrial Engineers (IIE) endorses the Canon of Ethics provided by the Accreditation Board for Engineering and Technology (ABET) whose first principle is that engineers uphold and advance the integrity, honor and dignity of the engineering 
profession by using their knowledge and skill for the enhancement of human welfare and whose first canon is engineers shall hold paramount the safety, health and welfare of the public in the performance of their professional duties. ${ }^{7-8}$ ABET is the accrediting body for all engineering and engineering technology programs in the United States and thus has an important impact on the training of tomorrow's engineers and engineering educators.

Members of the American Institute of Chemical Engineers (AIChE) are challenged to uphold and advance the integrity, honor and dignity of the engineering profession by being honest and impartial and serving with fidelity their employers, their clients, and the public; striving to increase the competence and prestige of the engineering profession; and using their knowledge and skill for the enhancement of human welfare. ${ }^{9}$ To achieve these goals, AIChE members shall hold paramount the safety, health and welfare of the public and protect the environment in performance of their professional duties. There is neither elaboration on the idea of protecting the environment nor an identification on from whom or what shall it be protected.

Many other engineering disciplines exist, each with their own codes for ethical conduct. As can be seen from this review, a large percentage of the codes do not explicitly identify the environment as an important stakeholder in discussions of the ethics of engineering choices. Equally as troubling, those codes that do mention the environment refer to the idea of enhancing nature or promoting sustainable development, which is based solely upon meeting human needs. A select few number of codes do mention a responsibility to protect the environment but without identifying from whom or from what.

There are many other engineering disciplines at present, each with its own code of conduct or ethics, which describes the responsibilities of the profession. Most focus heavily on the sense of responsibility engineering has towards employers, society in general and towards other professional engineers.

In their totality, the codes of ethics point to a very different conception or understanding of the natural world then our science provides us with now. We are at once removed from membership in the natural world as there is a listing of responsibilities of the engineering profession to humankind and if it exists at all a sense of responsibility to the natural world only in so far as it can provide something for us. We are not products of the earth but somehow placed on it with a focused plan of action set in place to tame it, control it, and to transform it into what suits are interests.

\section{Philosophical Origins of Present Day Codes}

Modern engineering in many respects begin with the Renaissance period in Western Europe. Humankind's understanding of or model for the natural world radically shifted from the notion of the Great Chain of Being ${ }^{10}$ prevalent during the medieval period to the Universe as a mechanical clock. ${ }^{11}$ The Great Chain of Being is a powerful visual metaphor for a divinely inspired universal hierarchy ranking all forms of higher and lower life; humans are represented by the male alone. The top of the chain represents

perfection in the highest degree. Most believers in the chain call this God. The chain in its 
entirety represents all degrees of perfection from the highest and fullest to the lowest and least; it is complete. ${ }^{12}$ Hence the universe would not be complete if the chain did not extend all the way to the bottom or if it had gaps in it. The universe is more perfect (in the sense that it is more complete) if all degrees of perfection are represented in it than if only the highest is represented. Eco described this paradigm as "a place for everything and everything in its place." 13

\begin{tabular}{||l|l|l||}
\hline \hline $\begin{array}{l}\text { CODE OF } \\
\text { CONDUCT }\end{array}$ & RELEVANT CANONS AND PRINCIPLES & $\begin{array}{l}\text { ATTITUDES TOWARDS } \\
\text { NATURE }\end{array}$ \\
\hline NSPE & hold paramount the safety, health, and welfare of the public. & No explicit reference \\
\hline ASME & $\begin{array}{l}\text { uphold and advance the integrity, honor, and dignity by using } \\
\text { their knowledge and skill for the enhancement of human } \\
\text { welfare. }\end{array}$ & No explicit reference \\
\hline ASCE & $\begin{array}{l}\text { hold paramount the safety, health and welfare of the public } \\
\text { and shall strive to comply with the principles of sustainable } \\
\text { development }\end{array}$ & $\begin{array}{l}\text { Sustainable development } \\
\text { linked solely to meeting } \\
\text { human needs }\end{array}$ \\
\hline IIE & $\begin{array}{l}\text { accept responsibility in decisions consistent with the safety, } \\
\text { health and welfare of the public, and to disclose promptly } \\
\text { factors that might endanger the public or the environment. }\end{array}$ & $\begin{array}{l}\text { Endangering environment } \\
\text { not explored }\end{array}$ \\
\hline IIE (ABET) & $\begin{array}{l}\text { shall hold paramount the safety, health and welfare of the } \\
\text { public in the performance of their professional duties }\end{array}$ & No explicit reference \\
\hline AIChE & $\begin{array}{l}\text { hold paramount the safety, health and welfare of the public } \\
\text { and protect the environment }\end{array}$ & $\begin{array}{l}\text { Protecting the environment } \\
\text { not explored }\end{array}$ \\
\hline
\end{tabular}

Table 1. Attitudes toward the Natural World in Codes of Conduct from Various Professional Engineering Societies.

Galileo is credited with being responsible for one of the most significant revolutions in thought in the development of the Western world and is referred to by many scholars as the originator of experimental science. In fact the term "revolution" was coined in response to his opinion that our Earth was one of several planets that revolved around the sun. ${ }^{14}$ The work of Galileo as well as many other natural philosophers led to the Age of Enlightenment, which refers to the 18th century in European philosophy, and is often thought of as part of a larger period, which includes the Age of Reason.

Within the "enlightenment" movement, rationality was advocated as a means to establish an authoritative system of ethics, aesthetics, and knowledge. The intellectual leaders of this movement regarded themselves as courageous and elite, and regarded their purpose as leading the world toward progress and out of a long period of doubtful tradition, full of irrationality, superstition, and tyranny which they believe characterized the medieval period. Nature possessed only instrumental value and thus must be not only managed or 


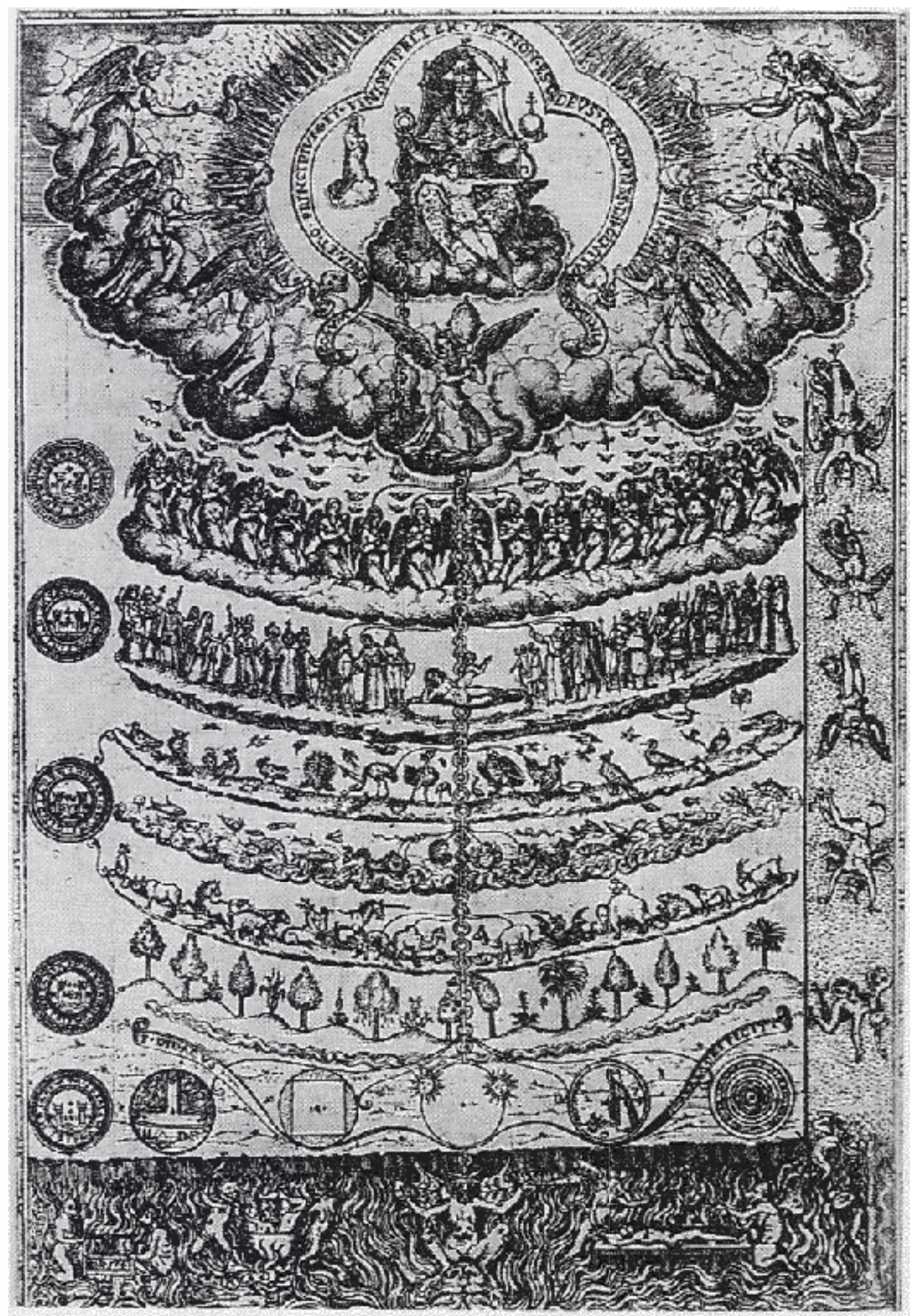

Figure 1. Great Chain of Being a powerful visual metaphor for a divinely inspired universal hierarchy ranking all forms of higher and lower life; the male alone represents humans. From Didacus Valades, Rhetorica Christiana (1579). Reproduced here from Anthony Fletcher's Gender, Sex,\& Subordination. ${ }^{12}$ 
controlled but transformed into useful resources that fed the insatiable appetites of progress. The visual metaphor used to depict the natural world became the mechanical clock rather than the Great Chain of Being.

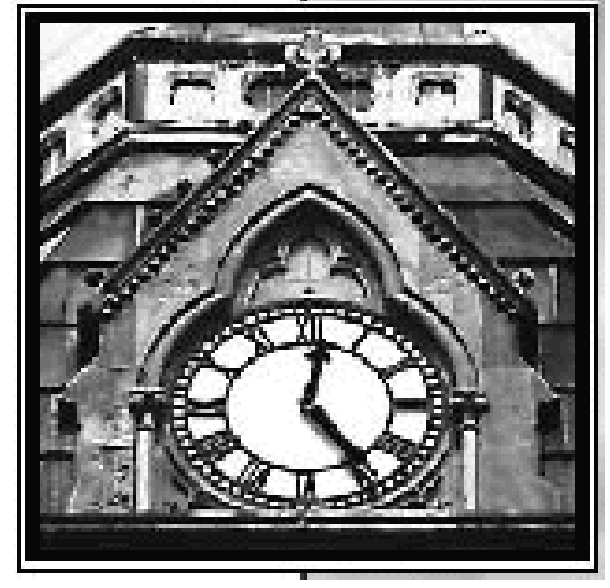

Figure 2. Mechanical Clock as Metaphor for Nature (The Tower Clock of the Cathedral Church of St. James, Toronto)

There was a second revolution, a moral one, which resulted from Galileo's findings. Man was believed to have been made in God's image, was the completion and moral center of the created world. If Galileo was right, man held an insignificant position in the physical universe which did not seems fitting for the moral center of the universe. Physical centrality was understood to signify moral centrality, and Galileo appeared to be denigrating the dignity of man and thereby denying God's scheme of values.

The belief that humanity is the moral center of the universe has had lasting endurance. There have been dissenting voices but the predominant view has been that humans are, rightly, of overriding or exclusive moral significance. In our actions regarding the nonhuman world, we have usually only been concerned with human values. Our goals, our technologies, have focused on how best to utilize the natural world to benefit humans. Various religious and secular reasons have been given for our pre-eminent moral standing. Humans unlike the lower animals are said to have souls or to be morally superior because of their rationality. Or humans are said to deserve our privileged position because of our seemingly victorious evolutionary struggle or simply because we have made up the rules.

Consider the attitudes towards the natural world expressed by the various engineering societies as listed in Table 1. Clearly, those attitudes originated in the scientific and philosophical theories of the Age of Enlightenment. Engineers should care about nature if at all only if it serves the interests of humankind. Nature has no intrinsic value only instrumental value. Nature needs to be managed, controlled and manipulated to serve us.

Other metaphors have been used to model the natural world. One which had some notoriety in the late $20^{\text {th }}$ century was the Gaia hypothesis. ${ }^{15}$ In 1965 , J.E. Lovelock published the first scientific paper suggesting the Gaia hypothesis. The Gaia hypothesis 
states that the temperature and composition of the Earth's surface are actively controlled by life on the planet. It suggests that if changes in the gas composition, temperature or oxidation state of the Earth are caused by extra-terrestrial, biological, geological, or other disturbances, life responds to these changes by modifying the abiotic environment through growth and metabolism. In simpler terms, biological responses tend to regulate the state of the Earth's environment in their favor.

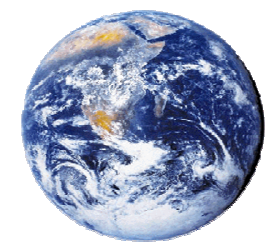

Figure 3. The Gaia Hypothesis: A revolutionary hypothesis that states that the Earth is alive.

Modern science at the start of the $21^{\text {st }}$ century does not model the natural world using either the great chain of being or the mechanical clock paradigms or as living being (Gaia hypothesis). Today the natural world is most often described using the model of a selforganizing system and nature rather than being thought of as immutable is seen as constantly in change. Self-organization refers to a process in which the internal organization of a system, normally an open system, increases automatically without being guided or managed by an outside source. Self-organizing systems typically (though not always) display emergent properties. Emergence is the process of complex pattern formation from simpler rules. This can be a dynamic process (occurring over time), such as the evolution of the human brain over thousands of successive generations; or emergence can happen over disparate size scales, such as the interactions between a macroscopic number of neurons producing a human brain capable of thought (even though the constituent neurons are not themselves conscious). For a phenomenon to be termed emergent it should generally be unpredictable from a lower level description.

The world abounds with systems and organisms that maintain a high internal energy and organization in seeming defiance of the laws of physics. ${ }^{16}$ According to Decker, "As a bar of iron cools, ferromagnetic particles magnetically align themselves with their neighbors until the entire bar is highly organized. Water particles suspended in air form clouds. An ant grows from a single-celled zygote into a complex multicellular organism, and then participates in a structured hive society. What is so fascinating is that the organization seems to emerge spontaneously from disordered conditions, and it does not appear to be driven solely by known physical laws. Somehow, the order arises from the multitude of interactions among the simple parts. The laws that may govern this selforganizing behavior are not well understood, if they exist at all. It is clear, though, that the process is nonlinear, using positive and negative feedback loops among components at the lowest level of the system, and between them and the structures that form at higher levels."

Decker goes on to add, "The study of landscape ecology provides an example of how an SOS perspective differs from standard approaches. Ecologists are interested in how 
spatial and temporal patterns such as patches, boundaries, cycles, and succession arise in complex, heterogeneous communities. Early models of pattern formation use a 'topdown' approach, meaning the parameters describe the higher hierarchical levels of the system. For instance, individual trees are not described explicitly, but patches of trees are. Or predators are modeled as a homogenous population that uniformly impacts a homogeneous prey population. In this way, the population dynamics are defined at the higher level of the population, rather than being the results of activity at the lower level of the individual."

Finally, "The problem with this top-down approach is that it violates two basic features of biological (and many physiochemical) phenomena: individuality and locality. By modeling a rodent population as a mass of rodents with some growth and behavior parameters, we obviate any differences that might exist between individual rodents. Some are big, some are small, some reproduce more, and some get eaten more. These small differences can lead to larger differences - such as changes in the population gene frequencies, individual body size, or population densities - that might have cascading effects at still higher levels. The tenet of locality means that every event or interaction has some location and some range of effect. This is a simple illustration of the ecological principle that pattern affects process. To say that a system is self-organized is to say it is not entirely directed by top-down rules, although there might be global constraints on the system. Instead, the local actions and interactions of individuals generate ordered structures at higher levels with recognizable dynamics. Since the origins of order in SOS are the subtle differences among components and the interactions among them, system dynamics cannot usually be understood by decomposing the system into its constituent parts. Thus the study of SOS is synthetic rather than analytic."

If the self-organized system is used to model the natural world rather than the great chain of being or the mechanical clock, our sense of responsibilities to the natural world seem to change significantly. We are forced to look "synthetically" rather than "locally," that is at the very least or moral sphere of concern must broaden. Secondly, nature is no longer in perfect order nor is it a collection of parts (i.e. gears, levers, weight) which can be replaced or modified according to our desires. The mechanical clock in many ways has been replaced by a seemingly chaotic clock which defies predictability, single-valueness and repeatability. If we are to make sense of our place in this natural world, we need a very different sense of ethics. One attempt at providing such an ethical framework has been offered by Johnson in his development of a morally deep world. ${ }^{17}$

\section{A Morally Deep World}

In A Sand County Almanac ${ }^{18}$, Leopold declares: "A thing is right when it tends to preserve the integrity, stability, and beauty of the biotic community. It is wrong when it tends otherwise." According to Leopold, acting ethically is a matter of concern both for us and for others with whom we are in some sort of community. The notion of a community deserves some discussion. We perhaps are most comfortable with community referring to a body of people having common rights, privileges, or interests, or living in the same place under the same laws and regulations; as, a community of Franciscan 
monks. In biology or ecology, community refers to an interacting group of various species in a common location. For example, a forest of trees and undergrowth plants, inhabited by animals and rooted in soil containing bacteria and fungi, constitutes an integral community. ${ }^{10}$ Extending the notion of community in this way is consistent with the pattern evidenced in human society over the centuries. We have progressively enlarged the boundaries of our understanding of community and recognized the membership of slaves, foreigners, etc., those for whom membership was not extended at earlier times in history. Leopold's land ethic then "simply enlarges the boundaries of the community to include soils, waters, plants, and animals, or collectively: the land."

Johnson discusses how non-sentient land can count morally and focuses upon the concept of a living being. ${ }^{18}$ For Johnson, a living being is best thought of not as a thing of some sort but as a living system, an ongoing life-process. A life-process has a character significantly different from those of other processes such as thermodynamics processes for example. Our character, as living beings, is the fundamental determinant of our interests. Johnson adds further that:

"The interests of a being lie in whatever contributes to its coherent effective functioning as an on-going life-process. That which tends to the contrary is against its interests....moral consideration must be given to the interests of all living beings, in proportion to the interest. Some living systems other than individual organisms are living entities with morally considerable interests. ...All interests must be taken into account."

The concept of a morally deep world was developed within the framework of environmental ethics. Perhaps it may be useful to explore the morally deep world argument as it applies to a specific and presently quite contentious issue in wildlife management today, the reintroduction of the Mexican wolf into regions of the Southwestern United States.. ${ }^{19}$ For the purposes of illustration, let us focus on the land near the White Sands Missile Range near Las Cruces, New Mexico. Johnson would challenge us to first identify all the members of the community. For this example a listing would include the following:

- Wolves

- Prey animals including domestic sheep and cattle as well as deer, rabbits, coyotes, and others

- Desert lands

- Ranchers and sheep farmers

- Hunters

- US Fish and Wildlife Service and other state and local government agencies

- US Department of Defense

- Residents of White Sands and nearby towns and settlements

- Residents of New Mexico and the entire United States

- Native American residents.

Often in such cases, two very different perspectives dominate the deliberations. On one side of the debate is atomism, a view that moral assessment applies only to individuals. 
The individual would be individual wolves, prey, ranchers, etc. On the other side is holism, a view that collectives or whole are subject to moral appraisal. In a morally deep world, the view is shortsighted morally if one adopts either a holistic or atomistic. No one (holistic or atomistic) interest has priority over the other. There is an inevitable tension between atomistic and holistic ethics. Sometime the interests of the biotic community will outweigh the interests of the individual, while at other times it is the interests of the individual, which are paramount. Let us next identify the extent of the community or living being in this case. Recall that a living being is characterized as having an ongoing life process with interests in whatever contributes to its coherent effective functioning. Clearly wolves, their prey, the desert lands, ranchers, sheep farmers, hunters and people who live in or near White Sands have considerable interests. Other identified elements could be argued to have less interest in the coherent effective functioning of the community. That is not to suggest that, for example, the residents in New York would have no interest in the restoration but their impact on the coherent effective functioning of the ongoing process would be less.

An interesting example of the tension between atomism and holism can be identified in the following scenario. Suppose wolves are restored to the White Sands Missile range desert and suppose that, as has been the case in Yellowstone National Park, wolves adapt well and quickly grow in numbers. ${ }^{19}$ In Yellowstone, some wolves are routinely killed as part of wolf or game management practices. From a holistic perspective this may be morally acceptable but it would be difficult to justify the killing from an atomistic perspective. A morally deep world point of view would argue that both interests need to be considered carefully, including the interests of the entire park community and those of the "surplus" wolf.

One criticism often offered of a morally deep world perspective is that it prevents any action that will affect a community. On the contrary, though a morally deep perspective does assert actions that violate vital interests of the community or erosion of its selfidentity should be avoided, it requires active participation in the protection of the essential functions and the maintenance of the viability of life processes. Rather than calling for inaction, a morally deep world perspective suggests contemplation followed by direct and specific responses.

\section{An Engineering Code in a Morally Deep World}

Given a shift to a morally deep world paradigm, a new engineering code of conduct is outlined. The majority of existing codes are structured in similar if not identical ways with fundamental principles supported by fundamental canons. That same structure will be incorporated into the present work. For a morally deep world, the first fundamental canon and rule of practice is specified as:

Engineers, in the fulfillment of their professional duties, shall hold paramount the safety, health and welfare of the identified integral community. 
The fundamental difference between an ethical code based on a morally deep world versus the present codes is the replacement of the "public" by the "identified integral community." The important difference this substitution makes can be seen in the following set of cases.

\section{Case 1. A Plow for Mexican Peasant Farmers}

The case is described as follows: "There is a pressing need for a device to assist thirdworld peasant farmers in cultivating their small plots of land. This need has never been satisfactorily met by any of the plows currently available. This case involves the design of a plow which can fulfill this need."

The case study went on to identify important questions concerning the significance of the plow:

- For whom should the plow be designed?

- Will humans or animals be used to pull the plow?

- Is the design of the plow sensitive to the gender of the operator?

- Will the operator of the plow walk or ride?

- Should the plow be designed at all?

After careful ethical analysis using present codes, several conclusions are reached. First, it is stated that a designer cannot answer all of the questions posed. In order to do so, the engineer would not only have to do an enormous amount of research, but also have to know the particular social group for which the plow is being designed. Second, quite surprisingly, the stated purpose of the discussion of the case under the present codes did not intend to result in an engineer becoming "obsessed with the cultural and ethical aspects of her (sic) work that she loses sight of more narrowly engineering considerations." Third, the intent of the case study was to raise the issue of "problems of conscience" as they arise in engineering work.

In order to implement a morally deep world code, we will first have to identify members of the integral community. A listing may include:

- Peasant farmers

- Landowners

- Animals used in working the land

- Peasant society and culture

- Health of the land

- Indigenous society and culture

- Local society and culture

With such identified members of the community, the first two conclusions are very different. Whether or not a great deal of research on the various social groups is no longer an option for the engineer but required. Secondly, leaving aside "obsession", the engineer is required to be aware of the cultural and ethical aspects involve or technical aspects in the proposed design as well as the more narrowly defined engineering

Case 2. A Ticket Tearing Device for a Disabled Person 
Consider the case of David S., a young man who suffers from a variety of physical and metal disabilities. David was employed at a movie theater in his local community near Philadelphia. His primary responsibility was to welcome patrons as they went into the theater hall, taking their admission tickets, tearing them in half and placing the torn tickets into a receiving basket. As David had very limited strength in his hands, the lines of people seeking admittance would soon back up. It was determined by both his employer and social worker that some variety of device that would help David's pace would be a great aid. A team of senior engineering capstone design students selected this project and dedicated two semesters to the design, fabrication, testing evaluation and delivery of the final device.

During the two terms, David made several visits to the campus and he and the students became quite close. Delivery day became a highly publicized event with local officials, university officials, family and friends all in attendance along with local and national press. David thoroughly enjoyed the festivities and was immensely pleased by his device. At that time, the project seemed an incredibly successful effort for everyone. Subsequent to the celebration, David continued his work for a while as an attendant at the theater but soon things began to change. He became much more withdrawn than he had ever been and soon quit his job. The seeming depression became worse and worse notwithstanding the heroic efforts of his social worker. David now is completely withdrawn and in fact institutionalized.

For this case, the following questions concerning the significance of the ticket-tearing device can be asked:

- For whom should the ticket-tearer be designed? David? Or a generic client?

- Who will provide technical support for David after the project is finished?

- Who will provide emotional support for David after the project is finished?

- Is the design of the ticket-tearer sensitive to the particular situation of David?

- Is the entire project sensitive to the particular situation of David?

- Should the ticket-tearer be designed at all?

The identified members of the community may include:

- David

- David's family

- Technical support workers

- Counseling support

- Theater owner

- Theater patrons

- The physically and emotionally disabled

An objective judging of this case would clearly point to the fact that notwithstanding all the noblest of intentions, David is now worse off than ever before. An engineering team though they followed all appropriate engineering dictums of safety, durability, etc., delivered a device that ultimately may have contributed to the suffering of a young man. What if instead of the engineering codes of conduct and ethics in place today, a morally 
deep world approach is taken? What would the consequences of such an approach be in this particularly poignant case study?

I would suggest that such an approach would force a much broader consideration of all the factors at play in David's case. There would be consideration given to the impact of not only the device but also the associated attention that the project garnered, an integration of many more professional perspectives, a consideration of not only short term benefits but also those of a much longer time scale. A consideration of David's family and friends and their support for him would be factored into the design.

\section{Concluding Remarks}

Vesilund in his recent book, The Right Thing to Do, rightly points out that the code of ethics is a "fine, first but rough tool for making decisions in engineering." Vesilund also states that the present codes have virtually nothing to say about the environment nor do they spell out what, if any, responsibilities engineers have to non-human animals, plants or places. The present review of existing codes points to the validity of this assertion. A review of presently available case studies for engineering education also struggle with issues associated with social, and cultural impacts. The present work offers one approach to insuring each of these considerations is included in the engineering approach. The approach is based on the notion of a morally deep world first developed within the context of environmental ethics. The key to implementation of this approach is in the identification of key elements in what was referred to as the integral community, that is, both the different elements of a community in an analytical sense but also the community, as a whole, synthetically.

The present codes of ethics used in engineering date back to a period when the universe and all its parts were thought to be nothing more than a great and grand machine. Our understanding of the universe and the natural world here on Earth has dramatically changed since that era. Now, we speak of emergent properties in self-organized systems. I would suggest that it is time for us as engineering educators and engineers to consider adopting a new code of ethics based on our new understanding.

\section{References:}

1. Webster's On-line Dictionary, www.websterdictionary.org/definition/engineering

2. NSPE Code of Ethics, National Society for Professional Engineers, http://nspe.org/ethics/eh-1code.asp

3. ASME Code of Ethics of Engineers, American Society of Mechanical Engineers, http://asme.org/asmeorg/Governance/5431.doc

4. ASCE Code of Ethics, American Society of Civil Engineers, http://www.asce.org/inside/codeofethics.cfm

5. ASCE Code of Ethics, American Society of Civil Engineers, http://www.asce.org/inside/codeofethics.cfm\#note3 
6. IEEE Code of Ethics, The Institute of Electrical and Electronics Engineers, http://www.iee.org/portal/site/mainsite

7. IIE Code of Ethics, The Institute of Industrial Engineers, http://www.iienet.org/public/articles/details.cfm?id=79

8. 2006-2007 Criteria for Accrediting Engineering Programs, Accreditation Board for Engineering and Technology, http://www.abet.org/Linked\%20DocumentsUPDATE/Criteria\%20and\%20PP/E001\%2006-07\%20EAC\%20Criteria\%201219-05.pdf

9. AIChe Code of Ethics, American Institute of Chemical Engineers, http://www.aiche.org/About/Code.aspx

10. Botkin, Daniel, Discordant Harmonies: A New Ecology for the $21^{\text {st }}$ Century, Oxford University Press: New York 1990.

11. Mumford, Lewis, Technics and Civilization, Harvest/HBJ Books, 1963.

12. Gabbard, Christopher, Gender and Politics in Literature, 1688-1750, http://www.stanford.edu/class/engl174b/main_page.html

13. Eco, Umberto, The Open Work, Harvard University Press: Cambridge, Ma., 2005

14. Huff, Toby, An Age of Science and Revolution, 1600-1800, Oxford University Press: New York, 2005.

15. Lovelock, James E., Homage to Gaia: The Life of an Independent Scientist, Oxford University Press: New York, 2001

16. Decker, Ethan, "Self-Organizing Systems: A Tutorial in Complexity," University of New Mexico, Albuquerque, NM 87106, USA

17. Leopold, Aldo, A Sand County Almanac, Ballantine Books: New York, 1986.

18. Johnson, Lawrence, A Morally Deep World, Cambridge University Press: Cambridge, 1993

19. Fehr-Elston, Catherine, Wolfsong, Tarcher Press: New York, 2005

20. Engineering Ethics: A Plow For Mexican Peasant Farmers Department of Philosophy and Department of Mechanical Engineering Texas A\&M University NSF Grant Number DIR-9012252, http://ethics.tamu.edu/ethics/plow/plow.htm

21. Vesilund, P. Aaarne, The Right Thing to Do, $2^{\text {nd }}$ ed., Lakeshore Press; Woodsville, New Hampshire, 2006. 